\title{
Studies on Effect of Pre-Treatments on the Quality of Candy Prepared from Fresh Turmeric Rhizomes
}

\author{
P. G. Pawar ${ }^{1}$ and V. R. Chavan ${ }^{2 *}$ \\ ${ }^{1}$ Department of B.voc Food Processing, Preservation and Storage, Maharashtra \\ Mahavidyalaya Nilanga, Latur-431521, India \\ ${ }^{2}$ Department of Food Process Technology, MGM College of Food Technology, MGM Hills, \\ Gandheli, Aurangabad-431 007 (M.S.)-India \\ *Corresponding author
}

The present investigation was carried out to study the Studies on effect of pre-treatments on the quality of candy prepared form fresh turmeric rhizomes. Results obtained indicated that the steam blanching found to be

Keywords

Pre-treatment, fresh turmeric rhizomes, Candy

Article Info

Accepted:

12 June 2021

Available Online:

10 July 2021 superior over all other treatment because of least loses in curcumin content. Further, alum treated sample $\left(\mathrm{T}_{\mathrm{A}}\right)$ candy was found to be superior in all the sensory attributes and also statically significant in all sensory characteristic over the other sample. Alum treated sample $\left(\mathrm{T}_{\mathrm{A}}\right)$ attained highest softness and on the basis of statistical analysis significant difference was observed in moisture, acidity content of pretreated candy, may be due addition of salt and alum being a osmotic agent and alkaline in nature of alum. In present study it is revealed that the effect of various pre treatments on chemical composition and organoleptic qualities of turmeric candy indicated that turmeric rhizome treated with alum was found superior results for sensory and chemical preparation turmeric candy and alum was shown superior effect on sensory characteristics of turmeric candy.

\section{Introduction}

Turmeric is a spice native to India. Historically, turmeric has been used throughout India, China and Indonesia as a spice and medicinal agent. Turmeric is a mild spice that enhances the flavour of other spices and foods and is the base of most Indian curries. In the Ayurvedic tradition, turmeric, or "haldi" as it is known in Hindi, works well with all doshas, with its main action being to reduce mucus from the system (De Jager and Prashanti, 2010). Turmeric is considered to be one of the most important herbs in the 
Ayurvedic tradition. The medical use of turmeric goes back more than 5000 years. Turmeric is ubiquitous in India and can be found in the turmeric plantations, herbal medicine preparations, spice bazaars, dyes and in food.

Turmeric has hundreds of molecular constituents, each with a variety of biological activities. For instance, there are at least 20 molecules that are antibiotic, 14 are known cancer preventives, 12 that are anti-tumor, 12 are anti-inflammatory and there are at least 10 different anti-oxidants. In fact, 326 biological activities of turmeric are known. This is also testimony to the use of whole herbs and not just isolated molecules. Speaking of molecules by far the most researcher in turmeric are the three gold-coloured alkaloids curcuminoids viz. Curcumin, Demethoxycuccumin and Bisdemethoxycurcumin. Most of the research done is with 95 per cent curcuminoids extract of turmeric, through in its raw state turmeric is only 3-5 per cent curcuminoids. The yield of essential oil in various parts is 1.3 per cent in leaf, 0.3 per cent in flower, 4.3 per cent in root and 3.8 per cent in rhizome (Leela et al., 2002).

Consumers are increasingly conscious about health and have begun to look at the nutritional benefits of food, disease prevention and health promoting compounds in many foods. At present there are many more constraints in processing of fresh turmeric rhizomes to have dried polished rhizomes which consume high energy and labour requirement. And hence there is an urgent need to develop the alternative technology for processing of fresh turmeric rhizomes without cooking, drying and polishing. With this intention and therapeutic importance of turmeric in the present investigation has been planned to study on utilization of fresh turmeric rhizomes in new product development like turmeric candy and soup with different pre-treatments (alum, salt, alum + salt) were also given to turmeric to reduce sourness/astringency and to improve acceptability.

\section{Effect of blanching treatment on curcumin content of turmeric with variation in time}

Blanching in hot water treatment removes the raw odour of turmeric and improves characteristics required for preparation of good quality products.

It was observed from table 1 that the unblanched turmeric rhizomes contained highest amount of curcumin content i.e. 5.3 per cent. The raw turmeric rhizome samples were boiled and steam blanched for 15, 20 and 25 minutes retained curcumin content 4.27 per cent, 3.97 per cent, 2.32 per cent and 4.32 per cent, 4.12 per cent, 4.04 per cent respectively. Also the values of curcumin content in the rhizomes blanched with sodium bicarbonate for time period of 15,20 and 25 minutes which recorded 4.18 per cent, 3.89 per cent and 2.30 per cent respectively. The data revealed that the maximum loss of curcumin content of turmeric was observed in case of rhizome treated by blanching with sodium bicarbonate than other treatments. The of loss curcumin content in boil blanched sample were more as compared to steam blanching. Blanched turmeric had lower total phenolic content and antioxidant activity compared to the untreated sample of turmeric due to the loss of phenolic into the hot water during blanching. Some studies reported that high temperatures, such as experienced in blanching, cause thermal degradation of curcumin. These results are good agreement with Chen et al., (2014). Similar pre treatments were also given by Thuwapanichayanan et al., (2014) for removal of raw odour of ginger and turmeric. It could be concluded that the steam blanching found to be superior over all other treatment because 
of least loses in curcumin content. The similar data on the blanching treatment reported by Patil et al., (2015).

\section{Effect of pretreatments on organoleptic evaluation of turmeric candy}

The turmeric rhizomes were pre treated with alum, salt and alum+ salt for preparation of candy. Then the prepared candy were subjected for sensory evaluation by semi trained panel members with respect to colour, appearance, flavour, taste and overall acceptability which was compared with control sample and results obtained are tabulated in Table 2 .

The data showed that among the four pre treatments of turmeric candy, colour and appearance of candy from alum treated sample $\left(\mathrm{T}_{\mathrm{A}}\right)$ recorded highest score i.e. 7.5 and 8.0 respectively followed by salt treated sample $\left(\mathrm{T}_{\mathrm{S}}\right)$ both scored 7.0. Whereas alum+salt treated sample $\left(\mathrm{T}_{\mathrm{AS}}\right)$ recorded 7.0 and 7.6 and control sample scored 6.5 respectively. The lowest score observed in control sample $\left(\mathrm{T}_{\mathrm{C}}\right)$ over the other samples.

Taste attribute of alum treated sample $\left(\mathrm{T}_{\mathrm{A}}\right)$ recorded highest score (7.8) as compared to other treatments, followed by alum + salt treated sample $\left(\mathrm{T}_{\mathrm{AS}}\right)$ scored (7.5), salt treated sample $\left(\mathrm{T}_{\mathrm{S}}\right)$ obtained lowest score (7.2).

The variation may be due to the unpleasant combination of sugar and salt. Least score was found by control sample i.e. (6.0). It may be due to the low penetration of sugar in the sample. The alum treated sample $\left(\mathrm{T}_{\mathrm{A}}\right)$ obtained highest score for flavour (8.0) and texture (7.8) followed by alum + salt sample $\left(\mathrm{T}_{\mathrm{AS}}\right)$, salt sample $\left(\mathrm{T}_{\mathrm{S}}\right)$ and control samples $\left(\mathrm{T}_{\mathrm{C}}\right)$ respectively. Minimum score was observed by control sample for flavour and texture i.e. (6.0) and (6.5) respectively.

It can be revealed that the alum treated sample $\left(\mathrm{T}_{\mathrm{A}}\right)$ were recorded highest overall acceptability score (7.8) which make it highly acceptable and also statically significant over other treatments of blanching sample. Moreover, among the rest three treatments, the alum + salt treated sample $\left(\mathrm{T}_{\mathrm{AS}}\right)$, salt treated sample $\left(\mathrm{T}_{\mathrm{S}}\right)$ and control sample $\left(\mathrm{T}_{\mathrm{C}}\right)$ was found to be least acceptable in all the organoleptic characteristics as compared to alum treated sample $\left(\mathrm{T}_{\mathrm{A}}\right)$.

Hence, it can be concluded that alum treated sample $\left(\mathrm{T}_{\mathrm{A}}\right)$ candy was found to be superior in all the sensory attributes and also statically significant in all sensory characteristic over the other samples. It can be further used for processing of good quality product and physicochemical analysis.

\section{Effect of pretreatments on chemical constituents of turmeric candy}

Pre-treatment is the initial step undertaken before osmosis process, to minimize the astringency, bitterness and sourness from fruits. And hence, efforts were made to improve its quality. The data pertaining to effect of pre-treatments on chemical composition of turmeric candy are tabulated in the Table 3.

There were minimum changes in the moisture content and TSS of the entire pre-treated sample, statistically values found to be at par with each other with respect to moisture content and TSS. It might be due to the difference in solute size, as smaller the size lead to higher water loss. The highest TSS was found in salt treated sample (Ts) $71.32^{\circ} \mathrm{Bx}$. 
Table.1 Effect of blanching treatment on curcumin content of turmeric with variation in time

\begin{tabular}{|c|c|c|}
\hline Treatment & Curcumin content (\%) & Time (min) \\
\hline Unblanched & 5.3 & 0 \\
\hline \multirow{2}{*}{ Boil blanching } & 4.27 & 15 \\
\hline \multirow{2}{*}{ Steam blanching } & 3.97 & 20 \\
\cline { 2 - 3 } & 2.32 & 25 \\
\cline { 2 - 3 } & 4.32 & 15 \\
\hline \multirow{2}{*}{ Boil +sodium bicarbonate } & 4.12 & 20 \\
\cline { 2 - 3 } & 4.04 & 25 \\
\cline { 2 - 3 } & 4.18 & 15 \\
\cline { 2 - 3 } & 3.89 & 20 \\
\cline { 2 - 3 } & 2.30 & 25 \\
\hline
\end{tabular}

*Each value is an average of three determinations

Table.2 Effect of pretreatments on organoleptic evaluation of turmeric candy

\begin{tabular}{|c|c|c|c|c|c|c|}
\hline Treatments & Appearance & Colour & Taste & Flavour & Texture & Overall acceptability \\
\hline $\mathbf{T}_{\mathbf{C}}$ & 6.5 & 6.5 & 6.0 & 6.0 & 6.5 & 6.8 \\
\hline $\mathbf{T}_{\mathbf{A}}$ & 8.0 & 7.5 & 7.8 & 8.0 & 7.8 & 7.8 \\
\hline $\mathbf{T}_{\mathbf{S}}$ & 7.0 & 7.0 & 7.2 & 7.0 & 7.5 & 7.3 \\
\hline $\mathbf{T}_{\mathbf{A S}}$ & 7.6 & 7.0 & 7.5 & 7.5 & 7.5 & 7.5 \\
\hline $\mathbf{S E}$ & 0.0083 & 0.096 & 0.0056 & 0.0169 & 0.0236 & 0.0066 \\
\hline $\mathbf{C D} @ \mathbf{5}$ & 0.0244 & 0.0282 & 0.0163 & 0.0498 & 0.0691 & 0.0193 \\
\hline
\end{tabular}

*Each value is an average of ten determinations

$\mathrm{T}_{\mathrm{C}^{-}}$Turmeric candy without pre treatment

$\mathrm{T}_{\mathrm{A}^{-}}$Turmeric candy with $2 \%$ alum treatment

$\mathrm{T}_{\mathrm{S}^{-}}$Turmeric candy with $2 \%$ salt treatment

$\mathrm{T}_{\mathrm{AS}}$-Turmeric candy with $2 \%$ alum and salt

Table.3 Effect of pre-treatments on chemical constituents of turmeric candy

\begin{tabular}{|c|c|c|c|c|}
\hline Sample & Moisture (\%) & $\begin{array}{c}\text { TSS } \\
\left({ }^{\circ} \mathbf{B x}\right)\end{array}$ & $\mathbf{p H}$ & Acidity (\%) \\
\hline $\mathbf{T}_{\mathbf{C}}$ & 28.74 & 69.25 & 4.10 & 0.56 \\
\hline $\mathbf{T}_{\mathbf{A}}$ & 27.85 & 70.15 & 4.06 & 0.59 \\
\hline $\mathbf{T}_{\mathbf{S}}$ & 26.65 & 71.32 & 4.07 & 0.57 \\
\hline $\mathbf{T}_{\mathbf{A S}}$ & 27.35 & 70.72 & 4.06 & 0.58 \\
\hline $\mathbf{S E} \pm$ & 0.1023 & 0.2439 & 0.0106 & 0.0012 \\
\hline $\mathbf{C D}$ at 5\% & 0.3002 & 0.7155 & 0.031 & 0.0036 \\
\hline
\end{tabular}

*Each value is an average of three determinations 
Salt, being a smaller solute, penetrate to a much greater depth and lead to higher water loss (Lenart and Flink, 1984), was desirable to maintain its nutritional profile. The TSS content in the sample $\mathrm{T}_{\mathrm{AS}}$ and $\mathrm{T}_{\mathrm{A}}$ were found to be 70.72 and $70.15^{\circ} \mathrm{Bx}$. And the untreated control sample $\left(\mathrm{T}_{\mathrm{C}}\right)$ maintained at $69.25^{\circ} \mathrm{Bx}$. These results are consistent with the results of Patel, (2013) who investigated the influence of pre-treatment ( 2 per cent salt, 2 per cent alum, 2 per cent salt+alum, control) on bio-chemical quality of aonla murabba.

The highest acidity was found in alum treated sample $\mathrm{T}_{\mathrm{A}}(0.59$ per cent $)$, followed by the acidity of other samples such as $\mathrm{T}_{\mathrm{AS}}(0.58$ per cent), $T_{S}(0.57$ per cent $)$ and control sample $T_{C}$ (0.56 per cent). Similar findings were observed by Pant et al., (2004), in sugar based aonla candy. There were heavy leaching losses of acids during blanching. Prajapati et al., (2011) reported the similar acidity in KMS blanched and hot water blanched aonla shreds. Both the investigation implicates that leaching is the reason for reduction of acidity. Moreover, pre-treatments affected the titrable acidity of candy which further aid in improving the quality of product by reducing the bitterness and astringency.

Alum treated sample $\left(\mathrm{T}_{\mathrm{A}}\right)$ attained highest softness. Followed by alum + salt $\left(\mathrm{T}_{\mathrm{AS}}\right)$, salt treated sample $\left(\mathrm{T}_{\mathrm{S}}\right)$ and control sample $\left(\mathrm{T}_{\mathrm{C}}\right)$ shown decreases in the softness of turmeric candy respectively and on the basis of statistical analysis statically significant difference was observed in moisture, acidity content of pretreated candy, may be due addition of salt and alum being a osmotic agent and alkaline in nature of alum. Similar results were obtained for effect of blanching on turmeric rhizomes processing as investigated by Patil et al., (2015).

The good quality turmeric candy and soup prepared with respect to superior organoleptic attributes can be prepared with Blanched with 2 percent alum, a good quality turmeric candy can be prepared with addition of 10 percent lemon and ginger juice respectively. The prepared candy was found to be the organoleptically acceptable.

\section{References}

Chen L., Bai G., Yang S., Yang R., Zhao G., $\mathrm{Xu}$ C. and Leung W. (2014). Encapsulation of curcumin in recombinant human $\mathrm{H}$-chain ferritin increases its water-solubility and stability. International Food Research Journal, 162:1147-1153.

De J. and Prashanti. (2010). Turmeric: The Ayurvedic Spice of Life, 2nd ed. Pioneer Imprints, 11-12.

Leela N. K., Tava A., Shaf P. M., John S. P. and Chempakam B. (2002). Chemical Composition of essential oils of turmeric (Curcuma longa L.). Acta Pharmaceutica Journal, 52(2): 137141.

Lenart A. and Flink J. M. (1984). Osmotic concentration of potato. Spatial distribution of the osmotic effect. International Journal of Food Science and Technology, 19(1):65-89.

Pant K., Dhawan S. S., Goyal R. K. and Dhawan K. (2004). Effect of predrying treatments on nutritional quality of aonla (Emblica officinalis). Indian Food Packer, 58(5):67-69.

Patil R. R., Kurhekar S. P., Patil S. R. and Sawant S. R. (2015). Studies on effect of blanching on turmeric processing. International Journal of Tropical Agriculture, 33(2):901-903.

Prajapati V. K., Nema P. K. and Rathore S. S. (2011). Effect of pretreatment and recipe on quality of solar dried aonla (Emblica officinalis Gaertn) shreds. In: International Conference on Food security and environmental 
sustainability. Indian Institute of Technology, Kharagpur, 17-19

Thuwapanichayanan R., Phowong C., Jaisut D. and Stencl J. (2014). Effects of pretreatments and drying temperatures on drying characteristics, antioxidant properties and color of ginger slice. Acta University of Agriculture Silva Mendel Brun, 62(9):1125-1134.

\section{How to cite this article:}

Pawar, P. G. and Chavan, V. R. 2021. Studies on Effect of Pre-Treatments on the Quality of Candy Prepared from Fresh Turmeric Rhizomes. Int.J.Curr.Microbiol.App.Sci. 10(07): 216221. doi: https://doi.org/10.20546/ijcmas.2021.1007.023 